\title{
Implantes
}

\section{Propriedades mecânicas e de corrosão de dois aços inoxidáveis austeníticos utilizados na fabricação de implantes ortopédicos}

\author{
Enrico José Giordani \\ Dr. Eng. Mecânica, CCDM / UFSCar / UNESP. E-mail: enrico@ccdm.ufscar.br \\ Itamar Ferreira \\ Professor, Dr., DEMa / FEM / UNICAMP.E-mail: itamar@fem.unicamp.br \\ Oscar Balancin \\ Professor, Dr., DEMa / UFSCar.E-mail: balancin@power.ufscar.br
}

\section{Resumo}

Embora o aço inoxidável austenítico tipo ASTM F 138 seja o material metálico mais utilizado na fabricação de implantes ortopédicos, alguns aspectos como baixa resistência mecânica, quando na condição recozido, e suscetibilidade à corrosão localizada limitam o emprego mais amplo desse material. Recentemente, o aço inoxidável austenítico com alto nitrogênio de classificação ISO 5832-9 vem sendo indicado como substituto ao F 138, principalmente para aplicações mais críticas, envolvendo carregamentos mais severos e longos períodos de permanência no interior do corpo humano. Nesse trabalho, fez-se a caracterização das microestruturas dos dois aços, avaliaram-se, comparativamente, as propriedades mecânicas básicas, as propriedades de corrosão e de fadiga dos dois aços. O aço ISO 5832-9 apresentou comportamentos mecânico e eletroquímico bastante superior ao aço ASTM F138. A combinação dessas características rendeu a esse material melhor desempenho em fadiga em meio neutro e em meio agressivo. Avalia-se o papel do nitrogênio, tanto em solução sólida, quanto combinado com o nióbio formando a fase Z, e discutem-se os fatores que levam à superioridade nas propriedades do aço ISO 5832-9.

Palavras-chave: Biomateriais metálicos, aços inoxidáveis austeníticos, ISO 5832-9.

\begin{abstract}
ASTM F 138 austenitic stainless steel is extensively used as an orthopedic implant material. However, some aspects, such as low strength in the annealed condition and susceptibility to localized corrosion, limit wider use of this kind of steel. Recently, a high-nitrogen austenitic stainless steel, specified in the standard ISO 5832-9, has been indicated as an alternative to ASTM F 138 steel for more severe loading and permanent application inside the human body. In this work, microstructure, mechanical properties, corrosion resistance and fatigue behavior of both steels were determined and compared. ISO 5832-9 steel displayed better mechanical and corrosion behaviors than did ASTM F 138 steel. The combination of these features lead ISO steel to enhanced fatigue performance in both neutral and aggressive environments. Analyzed were the role of nitrogen in solid solution, combined with niobium in the Z-phase, and the factors that led to superior ISO 5832-9 properties.
\end{abstract}

Keywords: Metallic biomaterials, austenitic stainless steel, ISO 5832-9. 


\section{Introdução}

Os implantes ortopédicos são dispositivos que substituem, parcial ou totalmente, funções de parte do corpo humano. Alguns implantes, chamados temporários (por ex. as placas e parafusos estabilizadores de fratura), desempenham suas funções por um período preestabelecido, até que ocorra a recuperação do osso danificado e o implante possa ser removido. Já outros, chamados permanentes, como os implantes para substituir articulações do corpo humano (por ex. a prótese total de quadril), precisam desempenhar suas funções pelo resto da vida do paciente. Uma vez implantados, os biomateriais, necessariamente, entram em contado com os fluidos corpóreos. Esses fluidos, apesar de parecerem inofensivos, conseguem, ao longo do tempo, degradar, significativamente, a maioria dos materiais de considerável inércia química ${ }^{(1)}$. Adicionalmente, grande parte dos implantes ortopédicos é submetida a esforços mecânicos estáticos e/ou cíclicos, muitas vezes de magnitudes relevantes. Isso ocorre, principalmente, com implantes utilizados nas extremidades inferiores do corpo humano.

A combinação de elevada resistência mecânica e a degradação pela ação do meio fisiológico, isoladamente ou em combinação com esforços mecânicos cíclicos e/ou estáticos, fazem de alguns materiais metálicos os preferidos para a fabricação de implantes ortopédicos. Entre esses, o aço inoxidável austenítico de classificação ASTM F 138 (classe especial do aço AISI 316L para aplicações médicas) é o material mais amplamente utilizado até os dias de hoje ${ }^{(2)}$. Entretanto alguns aspectos como baixa resistência mecânica, quando na condição recozido, e suscetibilidade à corrosão localizada limitam, muitas vezes, o emprego mais amplo desse material para aplicações ortopédicas permanentes.

A necessidade de novos materiais metálicos para aplicações médicas levou ao desenvolvimento de uma nova classe de aços inoxidáveis austeníticos de alto nitrogênio de classificação ISO 5832-9. Esse material combina alta resistência mecânica, mesmo quando na condição recozido, e alta resistência à corrosão localizada. ${ }^{(3,5)}$ Essas características fazem-no um aço promissor, no sentido de substituir o aço F 138 na fabricação de implantes ortopédicos, principalmente para aplicações mais críticas, envolvendo carregamentos mais severos e longos períodos de permanência no interior do corpo humano. Embora o aço ISO 5832-9 já venha sendo utilizado como substituto do aço F 138 na fabricação de alguns tipos de próteses, o seu desempenho ainda não é totalmente conhecido. Esse trabalho teve como objetivo caracterizar e analisar as microestruturas, avaliar comparativamente as propriedades mecânicas básicas, as propriedades de corrosão e de fadiga em meio neutro e meio agressivo dos dois aços.

\section{Materiais e métodos}

Os materiais utilizados, nesse estudo, foram os aços inoxidáveis austeníticos que atendem as especificações das normas ASTM F 138-03 e ISO 58329 (1992), produzidos pela antiga Eletrometal S.A. e Villares Metals S.A., respectivamente. As composições químicas desses aços são apresentadas na Tabela 1. Os aços foram fornecidos na condição recozidos a $1030^{\circ} \mathrm{C}$ na forma de barras laminadas a quente com diâmetro de $15,87 \mathrm{~mm}$.

A caracterização microestrutural, por microscopia ótica, foi conduzida em amostras polidas e atacadas eletroliticamente com ácido nítrico $\left(\mathrm{HNO}_{3}\right)$ a $60 \%$. Partículas em forma de precipitados no aço ISO 5832-9 foram caracterizadas, aplicando-se a técnica de extração de precipitados por dissolução preferencial de fase, utilizando ataque eletrolítico em solução $10 \% \mathrm{HCl}$ em metanol. Após a dissolução, o eletrólito foi filtrado em membrana de PVDF (tamanho médio de poro de 0,22 m) e o resíduo extraído analisado por espectroscopia de energia dispersiva (EDS) em um microscópio eletrônico de varredura (MEV) e por difração de raios $\mathrm{X}$.

As propriedades mecânicas básicas foram determinadas através de ensaios de tração, conduzidos segundo a norma ASTM E 8M. A Figura 1(a) mostra as dimensões dos corpos de prova utilizados nos ensaios. As propriedades mecânicas cíclicas foram determinadas através de ensaios de fadiga axial, com base na norma ASTM E 1801. Os ensaios foram conduzidos com controle de tensão (tração-tração), razão de carregamento $\mathrm{R}=0,01$, sob uma onda senoidal e freqüência de $10 \mathrm{~Hz}$. A Figura 1(b) apresenta o desenho dos corpos de prova utilizados nos ensaios. Foram levantadas as curvas S-N (tensão máxima vs. número de ciclos até a fratura), em meio neutro (ao ar) e em meio agressivo, simulando o fluido corpóreo (solução aquosa de $\mathrm{NaCl}$ a $0,9 \%$ a $37^{\circ} \mathrm{C}$ ). Para os ensaios, em meio agressivo, foi utilizada uma câmara de acrílico, que permitiu a exposição da seção útil do corpo de prova à solução aquosa, que, aquecida em um banho, circulava no interior dessa câmara, enquanto o corpo de prova era solicitado ciclicamente, como ilustra, esquematicamente, a Figura 1(c).

O comportamento eletroquímico dos aços foi determinado a partir de ensaios de polarização cíclica potenciodinâmica (ASTM G 61-86) e de ensaio potenciostático de corrosão por risco. Os ensaios foram conduzidos a $22 \pm 2^{\circ} \mathrm{C}$ e o eletrólito empregado foi uma solução de $\mathrm{NaCl}$ a 0,9\%.O ensaio de polarização cíclica potenciodinâmica consistiu na realização de um ciclo completo de varredura de potencial, utilizando-se um potenciostato que também monitorava a den-

Tabela 1 - Composições químicas dos aços utilizados (\% em peso).

\begin{tabular}{cccccccccc}
\hline Material & $\mathbf{C}$ & $\mathbf{S i}$ & $\mathbf{C r}$ & $\mathbf{N i}$ & $\mathbf{M n}$ & $\mathrm{Mo}$ & $\mathrm{Nb}$ & $\mathbf{N}$ & $\mathbf{F e}$ \\
\hline F 138 & 0,01 & 0,52 & 17,4 & 14,1 & 1,74 & 2,08 & - & - & bal. \\
ISO 5832-9 & 0,02 & 0,16 & 21,1 & 10,6 & 3,62 & 2,44 & 0,42 & 0,37 & bal. \\
\hline
\end{tabular}


sidade de corrente desenvolvida durante a varredura. Amostras dos dois aços foram decapadas, embutidas em resina de poliéster e, posteriormente, lixadas e polidas. O contra-eletrodo utilizado foi de platina e o eletrodo de referência foi do tipo calomelano saturado (ECS). O potencial de início foi de $-750 \mathrm{mV}$ e a taxa de varredura empregada foi de $0,33 \mathrm{mV} / \mathrm{s}$. A reversão no sentido da varredura do potencial ocorria quando a densidade de corrente de corrosão anódica atingia o valor de $100 \mu \mathrm{A} / \mathrm{cm}^{2}$.O ensaio potenciostático de corrosão por risco consistiu na quebra, por esforço mecânico, da camada passiva, utilizando-se uma ferra- menta pontiaguda de material cerâmico. Esse procedimento foi efetuado com a aplicação simultânea de um potencial com uso de um potenciostato, que também monitora a corrente de corrosão desenvolvida antes, durante e após o risco.

\section{Resultados}

A Figura 2 mostra microestruturas de amostras na condição como-recebidas dos aços ISO 5832-9 e F 138. Ambas as estruturas são austeníticas, sendo que no aço ISO 5832-9, observa-se a presença de grande quantidade de precipitados. A Figura 3(a) mostra a morfologia das partículas extraídas e observadas por $\mathrm{MEV}$, indicando a presença de três tipos diferentes de partículas: (a) partículas com a forma de placas com o tamanho próximo a $15 \mu \mathrm{m}$, (b) partículas arredondadas com tamanho próximo a $2 \mu \mathrm{m}$ e (c) pequenas partículas com tamanho próximo a 0,3 $\mu \mathrm{m}$. A Figura 3b apresenta o difratograma obtido por difração de raios X sobre o resíduo extraído e, também, a representação da célula unitária da fase identificada. As partículas foram identificadas como sendo precipitados da fase $\mathrm{Z}$, com composição aproximada $\mathrm{CrNbN}$ e estrutura tetragonal com parâmetros de rede $a=3,035 \AA$ e $c=7,380 \AA^{(5)}$.

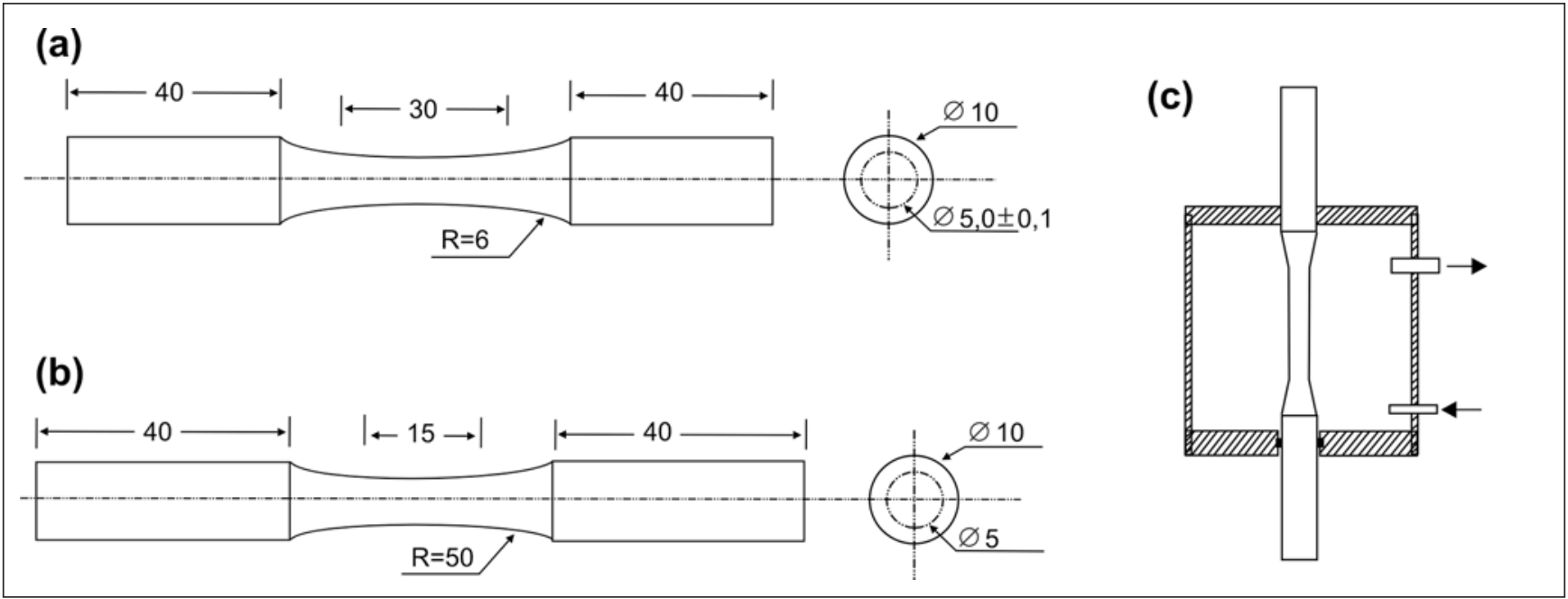

Figura 1 - Desenho dos corpos de prova utilizados nos ensaios de tração (a) e fadiga (b). Representação esquemática da câmara utilizada nos ensaios de fadiga(c).

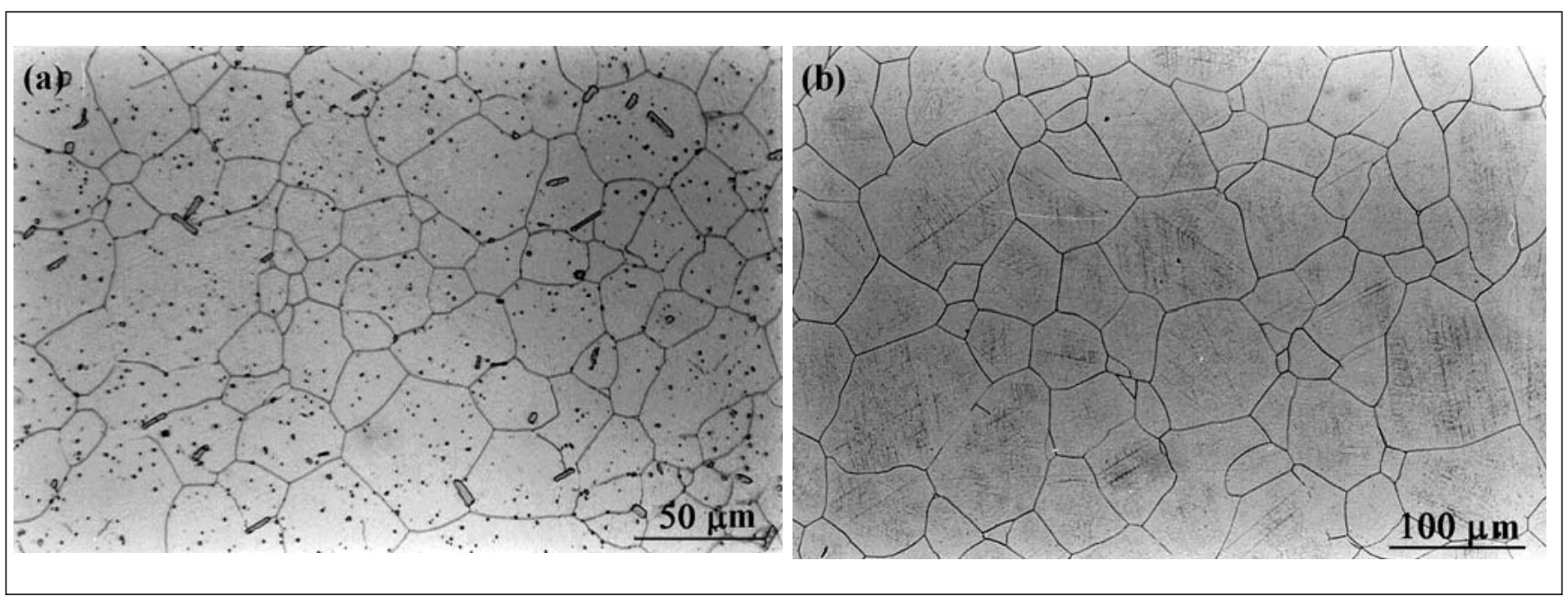

Figura 2 - Microestruturas de barras laminadas e recozidas a $1030^{\circ} \mathrm{C} / 1 \mathrm{~h}$, como recebidas. Aços (a) ISO $5832-9$ (tamanho médio de grão $\approx 15 \mu \mathrm{m}$ ) e (b) F 138 (tamanho médio de grão $\approx 63 \mu \mathrm{m}$ ). 


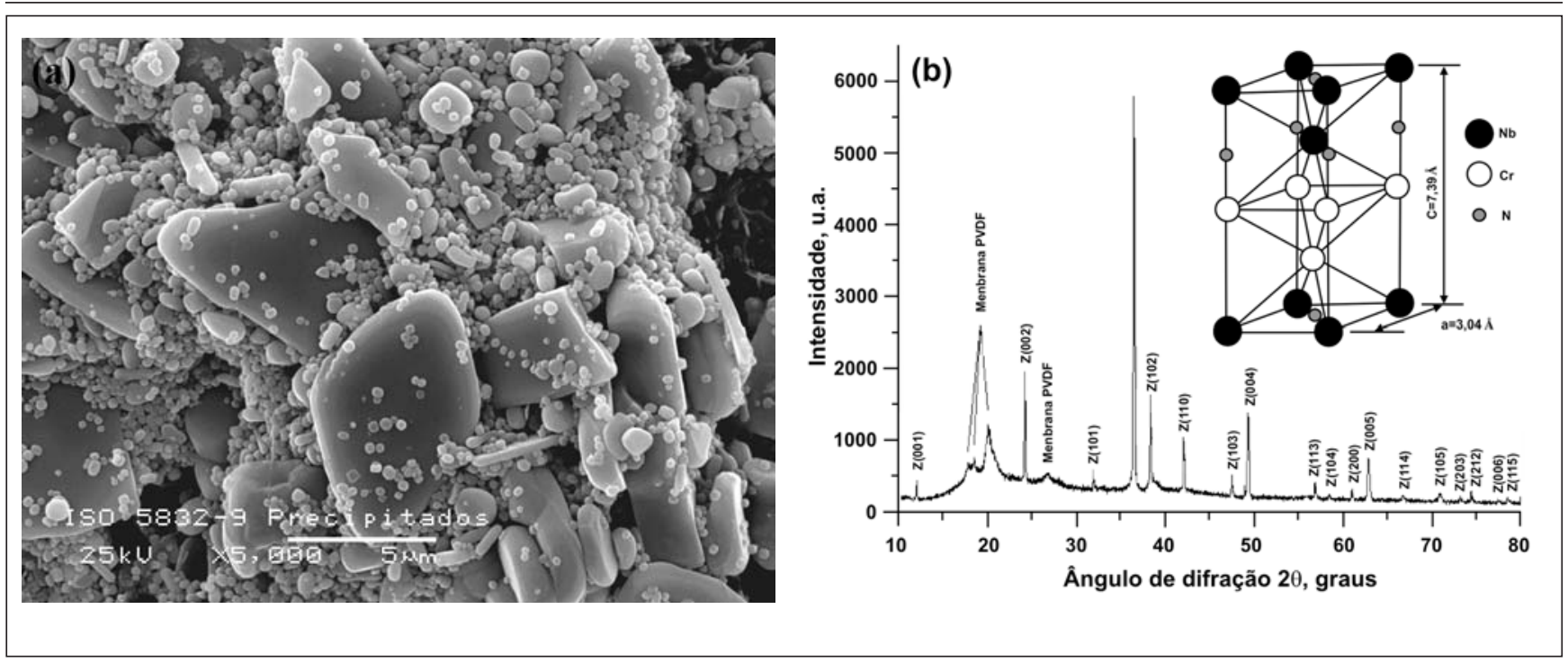

Figura 3 - (a) partículas extraídas do aço ISO 5832-9 observadas por MEV e (b) espectro de difração de raios X e representação da célula unitária da fase $\mathrm{Z}\left(\mathrm{Cr}_{2} \mathrm{Nb}_{2} \mathrm{~N}_{2}\right)$.

A Figura 4 mostra curvas tensãodeformação representativas obtidas no ensaio de tração para os dois aços estudados e a Tabela 2 apresenta os valores das propriedades mecânicas obtidas através desses ensaios. Pode-se ver que os dois aços atenderam, completamente, as especificações de propriedades mecânicas exigidas por suas respectivas normas (Tabela 2). O aço ISO 5832-9 apresenta níveis de resistência mecânica, limite de escoamento $\left(\sigma_{\mathrm{e}}\right)$ e limite de resistência à tração $\left(\sigma_{t}\right)$ muito superiores aos do aço F 138, sendo que o valor de $\sigma_{\mathrm{e}}$, para o aço ISO 5832-9, é, praticamente, o dobro do valor medido no aço F 138. Em contrapartida, a ductilidade desse material ( $\varepsilon_{\mathrm{t}}$ e RA) é, sensivelmente, menor, sem desqualificar o material para aplicações ortopédicas, tendo em vista que apresenta ductilidade superior ao exigido pela norma (Tabela 2).

O comportamento eletroquímico apresentado pelo aço F 138 no ensaio de polarização cíclica potenciodinâmica foi típico de materiais que apresentam potencial crítico de pite bem definido $\left(\mathrm{E}_{\mathrm{c}}=568 \pm 15 \mathrm{mV}(\mathrm{ECS})\right)$, conforme pode ser visto na Figura 5. Esse parâmetro define o potencial máximo acima do qual ocorre a quebra da passividade do material pela nucleação e propagação estável de um ou mais pites de corrosão. Como conseqüência da propagação estável do

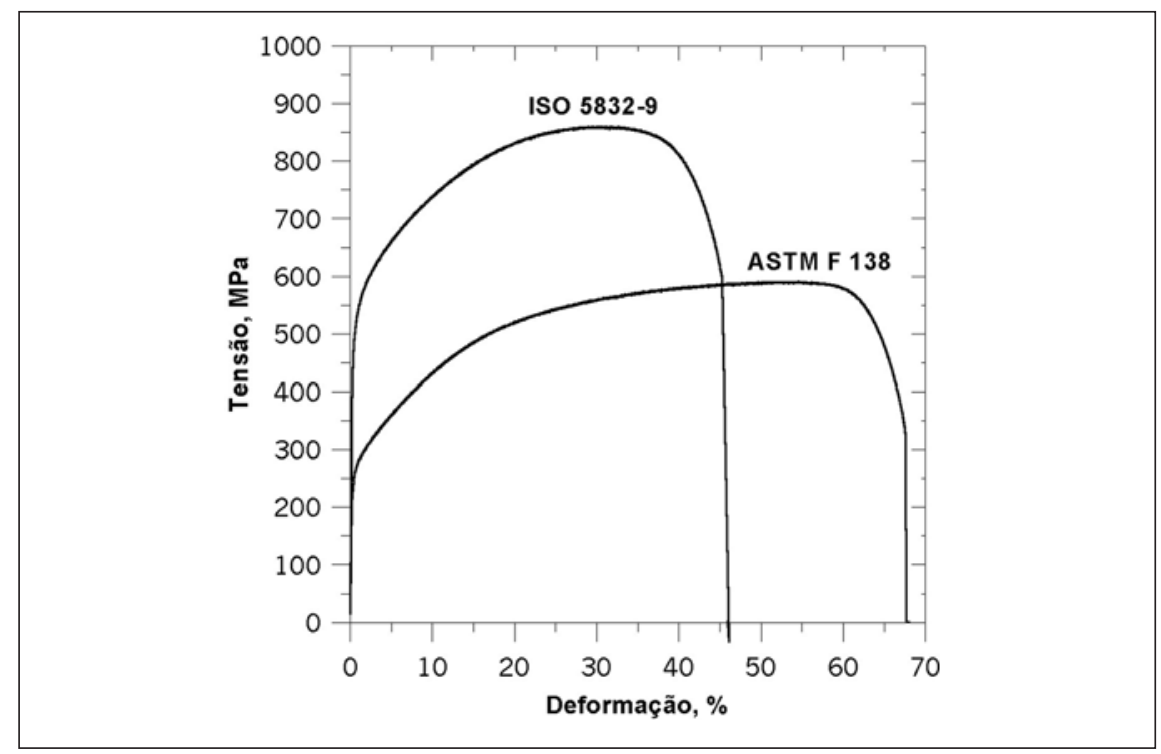

Figura 4 - Curvas tensão-deformação obtidas no ensaio de tração para os aços F 138 e ISO 5832-9.

Tabela 2 - Propriedades mecânicas dos aços F 138 e ISO 5832-9.

\begin{tabular}{ccc}
\hline Material & F 138 & ISO 5832-9 \\
\hline$\sigma_{\mathrm{e}}(\mathrm{MPa})$ & $246 \pm 3,0$ & $496 \pm 17,0$ \\
& $(170)$ & $(430)$ \\
$\sigma_{\mathrm{t}}(\mathrm{MPa})$ & $594 \pm 4$ & $861 \pm 3$ \\
& $(480)$ & $(740)$ \\
$\varepsilon_{\mathrm{t}}(\%)$ & $67,0 \pm 1,0$ & $46 \pm 0,7$ \\
RA (\%) & $(40)$ & $(35)$ \\
\hline
\end{tabular}

* Os valores entre parênteses representam os limites mínimos de propriedades admitidas pelas normas dos materiais. 
pite, ocorre um aumento abrupto da densidade de corrente de corrosão. Outro aspecto que confirma a ocorrência da corrosão por pites ${ }^{(6)}$ é o desenvolvimento de uma curva de histerese durante a varredura no sentido decrescente. A região da histerese caracteriza-se pelo crescimento dos pites nucleados no potencial crítico de pite e que não conseguiram repassivarem-se, mesmo para valores de potencial mais baixos que $\mathrm{E}_{\mathrm{c}}$, imediatamente após a reversão no sentido de varredura. Quando a histerese se fecha, cruzando a curva desenvolvida durante a varredura no sentido crescente, é definido o potencial de proteção $\left(\mathrm{E}_{\mathrm{p}}\right)$, abaixo do qual os pites nucleados são repassivados. Cahoon et al. ${ }^{(7)}$ indicam que a diferença entre o potencial crítico de pite e o potencial de proteção $\left(E_{c}-E_{p}\right)$, ou seja, o tamanho da histerese formada na curva de polarização, representa a resistência à corrosão em frestas do material ou mesmo a capacidade do material repassivar-se após experimentar o processo de corrosão ativa no interior do pite durante seu crescimento estável.

O aço ISO 5832-9 apresentou um comportamento eletroquímico diferente. O potencial crítico de pite para esse material não foi atingido. Essa afirmação é alicerçada pela ausência de um crescimento abrupto da densidade de corrente no intervalo de potencial estudado e, também, pela ausência de histerese durante a varredura de potencial no sentido decrescente, conforme pode ser observado na Figura 5. Dessa forma, é evidente que o aço ISO 5832-9 apresenta uma resistência à corrosão por pites muito superior à do aço F 138.

As Figuras 6a e 6b mostram o comportamento eletroquímico observado em ensaios potenciostático de corrosão por risco nos dois aços. Nesse ensaio, depois de constatada a estabilidade da película passiva por certo período $(\approx 120 \mathrm{~s}$ ) em um dado potencial, onde a densidade de corrente de corrosão deve manterse próxima de zero, a quebra mecânica do filme passivo (risco) é feita. Nesse instante, a densidade de corrosão apresenta um abrupto aumento. No caso de

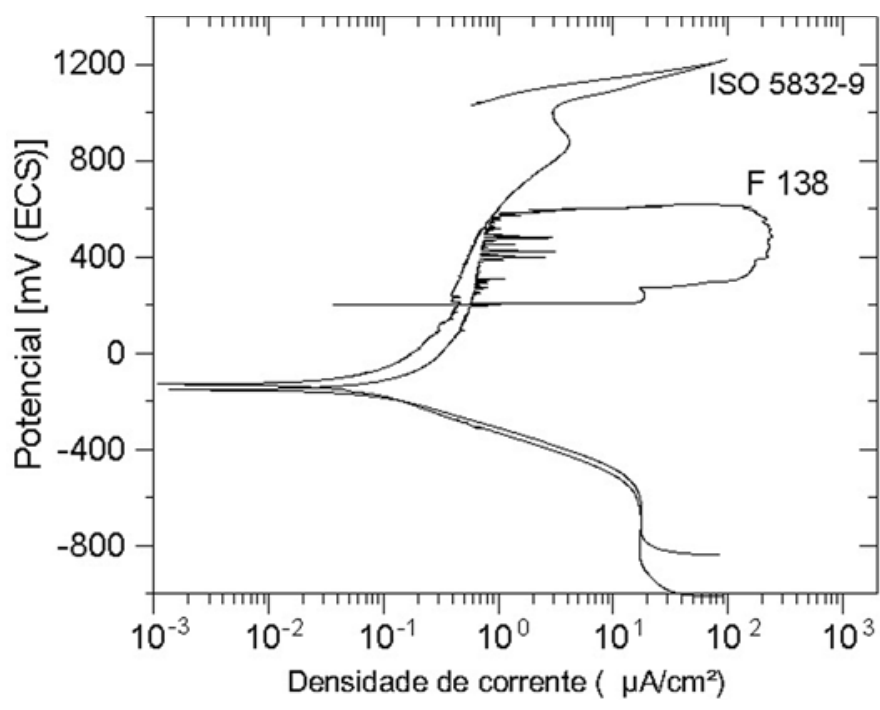

Figura 5 - Curvas representativas obtidas em ensaios de polarização cíclica potenciodinâmica em solução $0,9 \% \mathrm{NaCl}$ a $22^{\circ} \mathrm{C}$ dos aços F 138 e ISO 5832-9.

repassivação após o risco, a densidade de corrente deve decrescer, rapidamente, para valores próximos de zero. O potencial aplicado é, ainda, mantido durante algum tempo $(\approx 300 \mathrm{~s}$ ), para se verificar a estabilidade do filme, na região repassivada. A Figura 5a mostra que esse é o comportamento do aço ISO 5832-9, mesmo sob um potencial aplicado de $800 \mathrm{mV}$ (ECS). Por outro lado, quando a repassivação após o risco não ocorre, a densidade de corrente não se estabiliza em valores próximos de zero e aumenta com o tempo, como mostra a Figura 5b para o aço F 138 sob um potencial aplicado de 400 mV (ECS). Defini-se, então, o potencial crítico de pite $\left(\mathrm{E}_{\mathrm{c}}\right)$ como o potencial acima do qual a repassivação da superfície danificada pelo risco não mais ocorre. Nesse ensaio, o aço F 138 apresentou potencial crítico de pite médio de $427 \pm 34 \mathrm{mV}$ (ECS). Já o aço ISO 5832-9 demonstrou uma capacidade de repassivação muito maior, com valor de $\mathrm{E}_{\mathrm{c}}$ acima de $800 \mathrm{mV}$ (ECS), que é o valor limite do ensaio.

A Figura 7 traz as curvas S-N obtidas para os aços ISO 5832-9 e F 138, em meio neutro e meio agressivo. Observase que o aço ISO 5832-9 apresentou um desempenho em fadiga superior ao do aço F 138. Esse melhor desempenho se deve, principalmente, à maior resistência mecânica do aço ISO 5832-9. É notável a influência que o meio agressivo exerceu, no sentido de reduzir a vida em fadiga dos dois aços. Essa redução da vida aumentou com o aumento do número de ciclos até a fratura, ou mesmo com o tempo de ensaio, uma vez que a freqüência utilizada, para todos os corpos de prova foi igual.

\section{Discussão}

Os dois aços têm estrutura austenítica, não sendo observada, em nenhum deles, a presença de ferrita $\delta$. Ausência essa altamente desejável em materiais para aplicações ortopédicas, uma vez que a fase ferrítica é ferromagnética. Embora haja diferenças significativas nas composições químicas dos dois aços, a maior diferença microestrutural entre esses dois materiais é a presença da fase $\mathrm{Z}$ no aço ISO 5832-9. No aço com adições de nióbio e nitrogênio, as partículas identificadas como fase $\mathrm{Z}$ podem precipitar durante a solidificação e processamento ${ }^{(8)}$, dependendo dos teores de nióbio e de nitrogênio. As partículas que precipitam durante a solidificação têm tamanhos 
Propriedades mecânicas e de corrosão de dois aços inoxidáveis austeníticos utilizados...

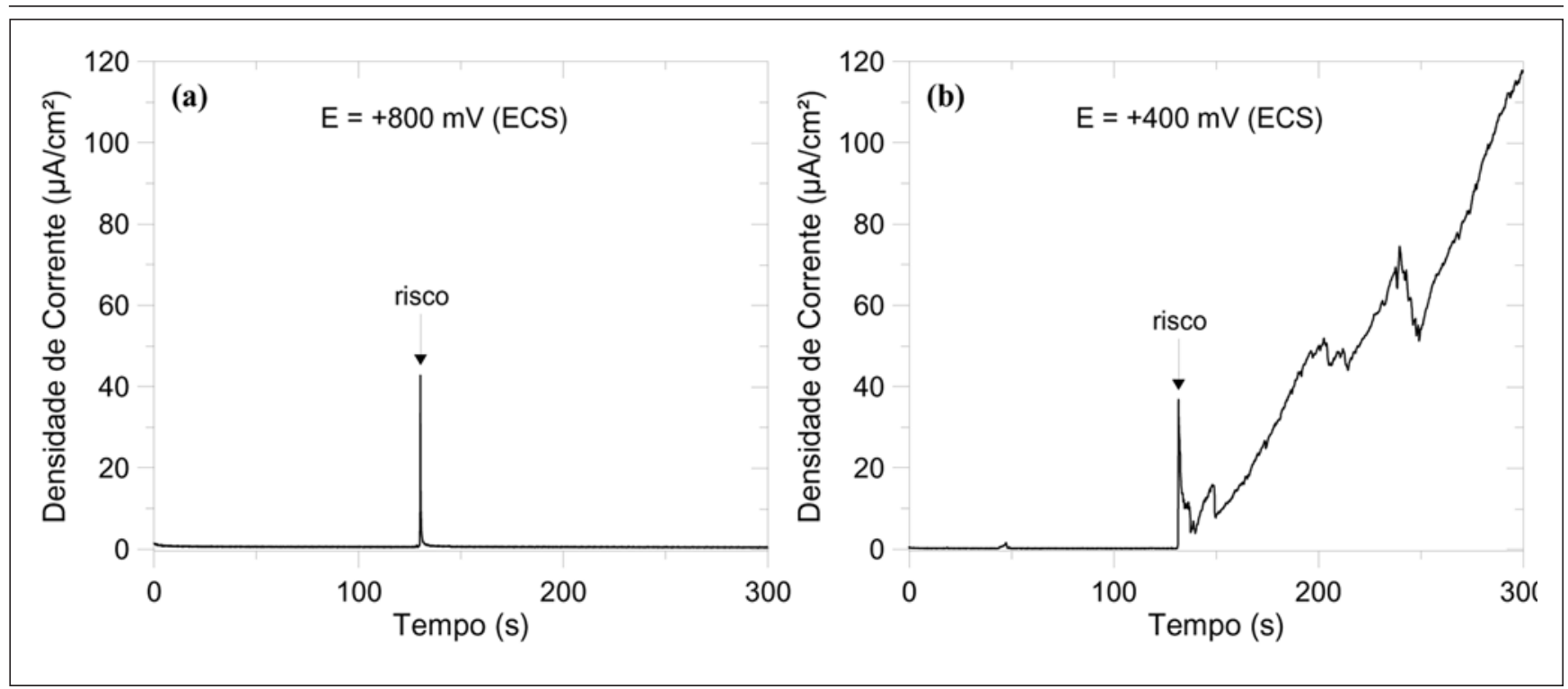

Figura 6 - Comportamento eletroquímico observado em ensaios potenciostático de corrosão por risco. (a) aço ISO $5832-9$ e (b) aço F 138.

maiores e se apresentam com a forma de placas, enquanto que as que se formam, durante o processamento ou tratamentos térmicos, são menores e têm a forma arredondada. No aço em estudo, nas condições de uso, o nitrogênio está na forma combinada e, também, em solução sólida( ${ }^{(3)}$.

A maior resistência mecânica do aço ISO 5832-9, em relação ao aço F 138, é atribuída, principalmente, à combinação de nitrogênio e nióbio presentes na composição do primeiro. Essas adições promovem o endurecimento pelo nitrogênio em solução sólida intersticial ${ }^{(9)}$, endurecimento pela precipitação de partículas da fase $\mathrm{Z}$ e endurecimento por refino de grão ${ }^{(10)}$, também atribuídos às partículas de precipitados da fase $\mathrm{Z}$, que ancoram o crescimento de grão durante o processo de recristalização do material. Além disso, o nitrogênio, em solução sólida, inibe os mecanismos de deslizamento cruzado e a escalagem de discordâncias, favorecendo, assim, o modo planar de deslizamento de discordâncias, durante a deformação plástica ${ }^{(10)}$. Em conseqüência, ocorre o aumento da eficiência dos contornos de grão como obstáculos à movimentação de discordâncias, tornando o mecanismo de endurecimento por refino de grão ainda mais eficaz.

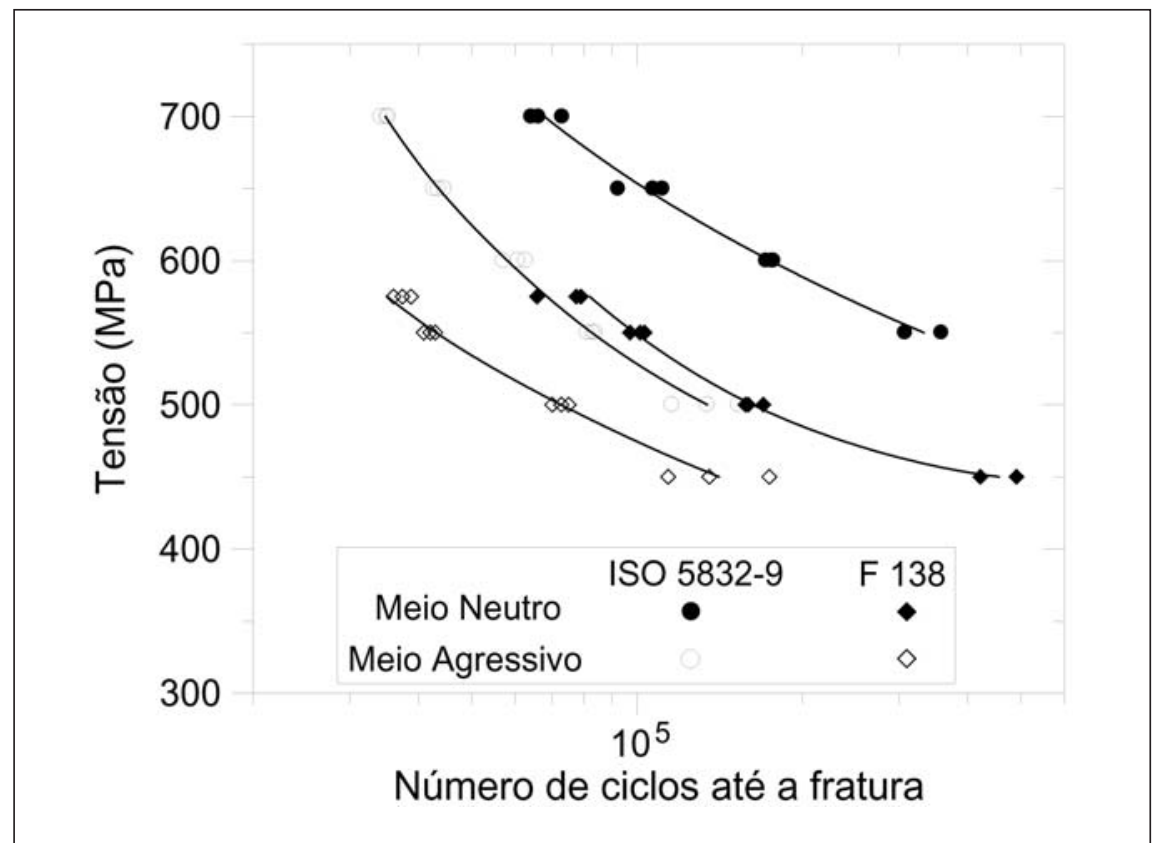

Figura 7 - Curvas tensão máxima (S) em função do número de ciclos (N) até a fratura em meio neutro e meio agressivo para os aços F 138 e ISO 5832-9.

A maior resistência à corrosão do aço ISO 5832-9 é, principalmente, atribuída ao aumento da estabilidade do filme passivo, favorecida pela presença do nitrogênio em solução sólida na austenita desse aço ${ }^{(11-14)}$. Vários pesquisadores observaram um enriquecimento em nitrogênio logo abaixo do filme passivo em aços com adição desse elemento. Grabke $^{(15)}$ sugere que o nitrogênio localizado na interface metal/filme passivo, logo abaixo do filme passivo, apresentase carregado negativamente $\left(\mathrm{N}^{\delta-}\right)$. A presença desse nitrogênio pode inibir a iniciação de um pite, suprimindo ou retardando a adsorção de íons agressivos $\mathrm{Cl}^{-}$ no filme passivo, devido à interação repulsiva entre essas duas espécies.

$\mathrm{O}$ aumento no valor de $\mathrm{E}_{\mathrm{c}}$, para $\mathrm{o}$ ensaio de corrosão por risco, pode, mais uma vez, ser atribuído ao nitrogênio em solução sólida no aço ISO 5832-9. Ime- 
diatamente após a quebra do filme passivo (mecanicamente neste caso), ocorre a segregação de nitrogênio carregado negativamente $\left(\mathrm{N}^{\delta-}\right)$ na superfície do metal, pela dissolução anódica da superfície desprotegida. Essa segregação promove a remoção dos íons agressivos $\left(\mathrm{Cl}^{-}\right)$pela interação repulsiva com as espécies segregadas $\mathrm{N}^{\delta-}$. Cria-se, então, condição suficientemente adequada para que a repassivação aconteça, mesmo em potenciais tão elevados quanto +800 mV (SCE).

Os ensaios de fadiga indicaram a influência que o meio agressivo exerce no sentido de reduzir a vida em fadiga dos dois aços. Sudarshan e colaboradores ${ }^{(16)}$ defendem que o contato com o meio agressivo tem o mesmo efeito sobre a vida em fadiga que o de um entalhe agudo usinado na superfície do metal, que, por sua vez, age como concentrador de tensões, facilitando a nucleação precoce de trincas por fadiga. Dessa forma, supõe-se que o meio corrosivo simplesmente facilita a formação de descontinuidades geométricas (pites de corrosão) na superfície previamente lisa de corpos de prova metálicos. Como esse processo é dependente do tempo, é coerente supor que a influência do meio agressivo aumente com o tempo de exposição do corpo de prova num dado meio, conforme observado.

Outro aspecto importante dos ensaios de fadiga e fadiga-corrosão é o fato de que a influência do meio agressivo sobre a vida em fadiga do aço ISO 5832 9 foi mais pronunciada que a do aço F 138. Essa diferença fica mais evidente para corpos de prova solicitados com cargas mais baixas (vida em fadiga mais longa). Entretanto as expectativas apontavam no sentido oposto, uma vez que o aço ISO 5832-9 apresentou propriedades mecânicas e de corrosão superiores às do aço F 138. Estudos sobre o mecanismo de nucleação de trincas por fadiga e fadiga-corrosão nesse aço ${ }^{(17)}$ mostraram que as trincas de fadiga nuclearam quase que exclusivamente em descontinuidades geométricas associadas com a ruptura de partículas de precipitados da fase Z. Essas descontinuidades geométricas, muitas delas geradas já no primeiro ciclo de carregamento, sob condições de deformação plástica, favorecem o estabelecimento de condições muito agressivas do eletrólito estagnado no seu interior, criando condições favoráveis ao processo de corrosão em frestas, que, por sua vez, contribui com a redução acentuada no período de nucleação de trincas por fadiga. $\mathrm{O}$ estudo sugere que a presença de partículas grosseiras da fase Z, no aço ISO 5832-9, favorece a formação de descontinuidades geométricas pela ruptura dessas partículas, prejudicando as propriedades de fadiga e fadiga-corrosão desse material. Entretanto a presença dessas partículas grosseiras pode ser eliminada com a redução do teor de nióbio na liga.

\section{Conclusões}

- A presença de uma grande quantidade de partículas de precipitados, caracterizados como fase $\mathrm{Z}$, na microestrutura do aço ISO 5832-9, é responsável pelo refino de grão desse material, quando comparado com o aço F 138.

- A combinação dos mecanismos de endurecimento pelo nitrogênio em solução sólida, de endurecimento por precipitação da fase $\mathrm{Z}$ e de endurecimento por refino de grão é responsável pela maior resistência mecânica do aço ISO 5832-9, quando comparado com o aço F 138.

- O melhor desempenho em corrosão do aço ISO 5832-9, quando comparado com o aço F 138, pode ser atribuído, principalmente, ao nitrogênio em solução sólida.

- A combinação de alta resistência mecânica e alta resistência à corrosão localizada sugere que o aço ISO 5832-9 é um material muito promissor para a fabricação de implantes ortopédicos, podendo substituir o aço F 138, principalmente em aplicações mais severas de carregamento e tempos longos de permanência no interior do corpo humano.

\section{Agradecimentos}

À FAPESP pelo apoio financeiro. À Baumer S.A. pelo fornecimento do material.

\section{Referências Bibliográficas}

1. BOSCHI, A.O. O que é necessário para que um material possa ser considerado um biomaterial. In: CONGRESSO ANUAL DA ABM, 50. 1995. São Pedro, SP, Brasil. Anais... São Pedro: ABM, 1995. v.6, p.43-53.

2. GOTMAN, I. Characteristics of metals used in implants. Journal of Endurology, v.11, n.6, p.383-389, 1997.

3. GIORDANI, E.J. Propriedades $e$ mecanismos de nucleação de trincas por fadiga em meio neutro e meio fisiológico artificial de dois aços inoxidáveis austeníticos utilizados como biomateriais. Campinas: FEM/ UNICAMP, 2001. (Tese de Doutorado).

4. OROZCO, C.P.O., ALONSOFALLEROS, N., TSCHIPTSCHIN, A.P. Estudo da resistência à corrosão dos diferentes tipos de aços inoxidáveis austeníticos utilizados em implantes cirúrgicos. In: CONGRESSO ANUAL DA ABM, 58. Rio de Janeiro, Brasil, 2003. Anais em CD ROM.

5. VILLAMIL, R.F.V. et alii. Comparative electrochemical studies of ISO 5832-9 and F 138 stainless steels in sodium chloride, pH = 4.0 medium”, ASTM STP 1438 G. In: WINTERS, L., NUTT, M. J. (Ed.). Americam Society for Testing and Materials. West conshohocken, PA, 2003.

6. RONDELLI, G., VICENTINI, B., CIGADA, A. Localized corrosion tests on austenitic stainless steels for biomedical applications. British Corrosion Journal, v.32, n.3, p.193-196, 1997.

7. CAHOON, J.R., BANDYOPADHYA, R., TENNESE, L. The concept of protection potential applied to the corrosion of metallic orthopedic implants. Journal of Biomedical Materials Research, v.6, p.259-264, 1975.

8. GIORDANI, E.J., JORGE Jr., A.M., BALANCIN, O. Evidence of straininduced precipitation on a Nb- and $\mathrm{N}$ bearing austenitic stainless steel biomaterial. Materials Science Forum, v.500, p.179-186, 2005. 
Propriedades mecânicas e de corrosão de dois aços inoxidáveis austeníticos utilizados...

9. NYSTRÖM, M. et alii. Influence of nitrogen and grain size on deformation behaviour of austenitic stainless steel. Materials Science and Technology, v.13, n.7, p.560-567, 1997.

10. STOLTZ, R.E., VANDER SANDE, J.B. The effect of nitrogen on stacking fault energy of Fe-Ni-Cr-Mn steels. Metallurgical Transactions A, v.11, 1p.033-1037, 1980.

11. PICKERING, F.B. Lille, France, 1988. Some beneficial effect of nitrogen in steels. In: INTERNATIONAL CONFERENCE ON NITROGEN STEELS. Proceedings... In: FOCT, J., HENDRY, A. (Ed.). London: The Institute of Metals, 1989 p.10-31.
12. LEVEY, P.R., BENNEKOM, A. A mechanistic study of the effects of nitrogen on the corrosion properties on stainless steels. Corrosion, v.51, n.12, p.911-921, 1995.

13. KAMACHI MUDALI, U. et alii. Relationship between pitting and intergranular corrosion of nitrogenbearing austenitic stainless steels. ISIJ International, v.36, n.7, p.799-806, 1996.

14. JARGELIUS-PETTERSSON, R.F.A. Electrochemical investigation of the influence of nitrogen alloying on pitting corrosion of austenitic stainless steels, Corrosion Science, v.41, n.8, p.16391664, 1999.
15. GRABKE, H.J. The role of nitrogen in the corrosion of iron and steels. ISIJ International, v.36, n.7, p.777-786, 1996.

16. SUDARSHAN, T.S., SRIVATSAN, T.S., HARVEY II, D.P. Fatigue processes in metals - role of aqueous environments. Engineering Fracture Mechanics, v.36, n.6, p.827-852, 1990.

17. GIORDANI, E.J. et alii. Effect of precipitates on the corrosion-fatigue crack initiation of ISO 5832-9 stainless steel biomaterials. International Journal of Fatigue, v.26, n.10, p.1129-1136, 2004.

Artigo recebido em 30/07/2006 e aprovado em 05/10/2006.

\section{Descubra as muitas informações da:} Geologia, Mineração,
Metalurgia \& Materiais e Engenharia Civil.

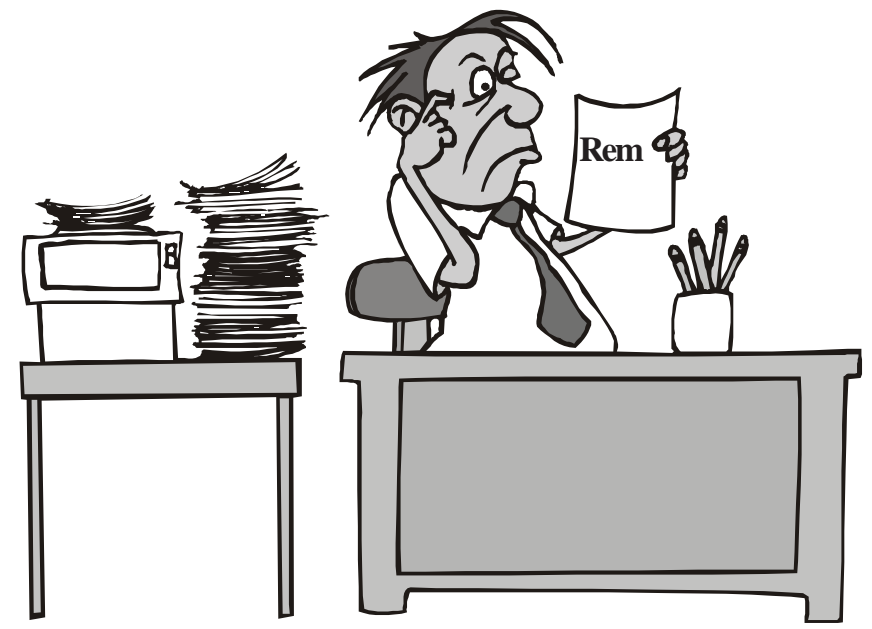

\section{Assine e publique na Rem}

Conheça o nosso novo site: WWW.rem.com.br 